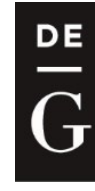

DE GRUYTER

OPEN

LEGE ARTIS

Language yesterday, today, tomorrow

Vol. III. No 12018

\title{
METAPHOR IN MEDIA LANGUAGE AND COGNITION: A PERSPECTIVE FROM CONCEPTUAL METAPHOR THEORY
}

\author{
Zoltán Kövecses \\ Eötvös Loránd University, Budapest, Hungary
}

Kövecses, Z. (2018). Metaphor in media language and cognition: A perspective from conceptual metaphor theory. In Lege artis. Language yesterday, today, tomorrow. The journal of University of SS Cyril and Methodius in Trnava. Warsaw: De Gruyter Open, 2018, III (1), June 2018, p. 124-141. DOI: 10.2478/lart-2018-0004 ISSN 2453-8035

\begin{abstract}
I discuss three large issues relating to media language. (1) How does conceptual metaphor theory affect the way we see the conceptual system that characterizes the main participants of communication in the media? (2) How do conceptual metaphors structure the language (and thought) used by the media? (3) Is the metaphorical mind of the participants of media communication a "selfcontained" mind immune to the influence of context or is it affected by it?
\end{abstract}

Keywords: media discourse, conceptual metaphor, virtual reality, coherence of media discourse, contextual effects, priming.

\section{Introdution}

It is only fair to state at the beginning that I am not a media expert in any sense. I am a consumer of media communication, but at the same time, I am a cognitive linguist, who is in a position to study and describe certain less studied forms and aspects of media communication that might benefit media communication in some ways. Within the field of cognitive linguistics, I work primarily on metaphor. The study of metaphor in cognitive linguistics began with the work of Lakoff and Johnson (1980). In the past almost 40 years, the ideas of Lakoff and Johnson have been refined and expanded (see Kövecses 2002/2010). "Conceptual metaphor theory" (CMT) is a burgeoning field that 
dominates the study of metaphor. Its dominance is in large part due to the fact that CMT made contact with a variety of disciplines and approaches in the study of the human mind and human behavior. In this paper, I attempt to provide some potentially useful links between CMT and media communication.

More specifically, I take a closer look at the following three general issues:

(1) Conceptual metaphors and their importance in media cognition;

(2) The role of conceptual metaphors in structuring media discourse;

(3) Contextual influence on metaphorical media discourse.

My emphasis will be on conceptualization in various forms of media communication, such as discourse by journalists, advertisements, headlines, pictures, and the like. It seems to me that it is the issue of conceptualization (i.e., how the mind creates and comprehends messages) (see Kövecses 2006) that is by and large missing from the study of media communication. A large part of the conceptualization process in the media involves metaphor. Thus, dealing with conceptualization in the media necessarily involves metaphorical conceptualization. But the focus on metaphor is relevant not only for the study of media language but also for topics such as multimodality, virtual reality, context, and even media ethics, as I try to show in the paper.

\section{Media cognition from a CMT perspective}

The standard definition of conceptual metaphors can be given as follows: A conceptual metaphor is a systematic set of correspondences, or mappings, between two domains of experience (see Kövecses 2017). The definition is a more technical way of saying what the well-known definition by Lakoff and Johnson (1980) states, according to which a conceptual metaphor is "understanding one domain in terms of another". In a conceptual metaphor, certain elements and the relations in a domain are mapped onto another domain. The domain, from which they are mapped is called the "source 
domain" and the domain onto which they are mapped is called the "target domain". We can illustrate how the correspondences, or mappings, work with the conceptual metaphor ANGER IS FIRE. But first, let us see some linguistic metaphors that realize this conceptual metaphor in English:

That kindled my ire.

Those were inflammatory remarks.

Smoke was coming out of his ears.

She was burning with anger.

He was spitting fire.

The incident set the people ablaze with anger.

Given such examples, the following set of correspondences, or mappings, can be proposed:

\author{
the cause of fire $\rightarrow$ the cause of anger \\ causing the fire $\rightarrow$ causing the anger \\ the thing on fire $\rightarrow$ the angry person \\ the fire $\rightarrow$ the anger \\ the intensity of fire $\rightarrow$ the intensity of anger
}

With the help of these mappings, we can explain why the metaphorical expressions listed above mean what they do: why, for instance, kindle and inflammatory mean causing anger. Further, the set of mappings is systematic in the sense that, together, they capture a coherent view of fire that is mapped onto anger. The mappings bring into correspondence the elements and the relations between the elements in the fire domain (source) with elements and the relations between the elements in the anger domain (target). In a sense, the mappings from the fire domain actually bring about or create a particular conception of anger relative to the view of fire. 
A major consequence of the idea that metaphors are conceptual in nature, i.e., that we conceive of certain things in metaphorical ways, is that, since our conceptual system governs how we act in the world, we often act metaphorically. When we conceptualize an intangible or less tangible domain metaphorically as, and from the perspective of, a more tangible domain, we create a certain metaphorical reality. This is very clear in those cases where two or more source domains are used to conceptualize a target domain. For instance, we imagine life one way when we think of it as a journey, and in another way when we think of it as a theater play, as reflected in Shakespeare's famous lines "All the world is a stage / and all men and women are merely players". The two source domains result in very different views on life, and in this sense, they create very different realities.

This kind of "reality construction" is very common in advertising, where, often, interesting or amusing cases of metaphorical reality get created. When advertisements for, say, deodorants promise "24-hour protection", they make us see a deodorant as our helper or ally in a fight or war against an enemy. The enemy is no other than our own body odour. So if we did not think of our body odour as our enemy before, i.e., as something we have to be protected against, the advertisements can easily make us view it as such. This novel and unconventional conceptual metaphor works with the following mappings:

enemy $\rightarrow$ body odor

attack $\rightarrow$ having the body odor

ally / helper $\rightarrow$ deodorant

protection $\rightarrow$ taking away body odor

In this manner, the metaphors used in advertisements and elsewhere can often create new realities for us. Such realities are of course metaphorically defined. If we think of our body odor as something we need to be protected against and as a result, we go and 
buy a deodorant to overcome the enemy, we are clearly thinking and acting according to a metaphorically-defined reality.

As a further consequence of conceptual metaphors, if metaphor is part of the conceptual system, it follows that conceptual metaphors will also occur in any mode of expression of that system. Research indicates that the conceptual metaphors identified in language also occur in gestures, visual representations (such as cartoons), visual arts (such as painting), and others (see, e.g., work by Forceville 2008; Cienki \& Müller 2008). For example, in some advertisements we talk to our cars and we give them names. These activities reflect affection. We also often treat cars as family members. In advertisements, cars are commonly represented visually as loved ones, people who can be hugged, carressed, and kissed. In such cases, the conceptual metaphor is ONE'S CAR IS A FAMILY MEMBER or A LOVED ONE. The frame of affection felt for the people we love is extended to inanimate objects like cars. This occurs frequently in product advertising. In such cases, a basic human emotion is extended to physical objects that do not normally trigger this response. In advertisements, then, a new, a virtual reality is created visually for a purpose: to say that the product will trigger the same positive emotion in us as family members and other loved ones do. This can enhance and is expected to enhance people's inclination and desire to buy the products.

\section{Metaphors structuring media discourse}

How do metaphors structure media discourse? There are essentially two ways in which they do: intertextually and intratextually. When they do so intertextually, the metaphors lend coherence to texts through space and time. When they do so intratextually, the metaphors lend coherence to a single text. However, we shall see in this section that these statements oversimplify the actual situation.

Let us begin with an example of intertextuality from what we can call "religious advertisement". In Durham, England, I was given a bookmark in Durham Cathedral with the following text on it: 


\author{
Almighty God \\ Who called your servant Cuthbert \\ from keeping sheep to follow your son \\ and to be shepherd of your people. \\ Mercifully grant that we, following his \\ example and caring for those who are lost, \\ may bring them home to your fold. \\ Through your son. \\ Jesus Christ our Lord. \\ Amen.
}

This is a good (though not prototypical) example of metaphorical intertextuality. It shows how a biblical metaphor has been recycled over the ages. Clearly, the text of the Bible is different from the text of the bookmark (a prayer), but the bookmark preserves a metaphor from the Bible. In it, we find the mappings below:

Source:

the shepherd

the lost sheep

the fold of the sheep

the shepherd bringing back the sheep
Target:

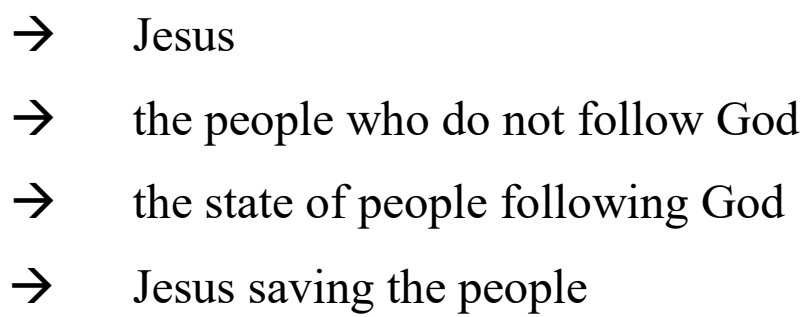

This metaphor was reused later on when God called a simple man, called Cuthbert, to give up his job and become a "shepherd of people". Here it is Cuthbert (not Jesus) who saves the lost people (a set of people different from the ones in Jesus' times). Finally, in the most recent recycling of the metaphor in the prayer said on St Cuthbert's day, $20^{\text {th }}$ March, 2007, the particular values of the metaphor change again. It is the priests 
who live today who try to bring people back to the fold - again, a set of people different from either those who lived in Jesus's or Cuthbert's times.

This type of intertextuality characterizes not only Christianity (and other religions) through time but many other domains within the same historical period. Thus, a conceptual metaphor can provide coherence across a variety of discourses both historically and simultaneously.

There are additional types of metaphorical intertextuality. They include common intertextual metaphors, such as the ones below:

- domino effect - one event causing a series of similar events

- $\quad$ red tape - excessive complexity in official routine

- $\quad$ tsunami of sg - overwhelming quantity or amount of sg

These metaphors occur in a wide variety of texts and in a wide variety of contexts that can diverge increasingly from the original first occurrence of the expressions. At the same time, the expressions preserve the metaphorical meanings given above.

Let us now take an example of metaphorical intratextuality, in which the same conceptual metaphor can lend coherence to a single text. This cognitive job can be performed by a conceptual metaphor, including metaphorical analogies of any kind. Consider the following three paragraphs, taken from the very beginning of a newspaper article:

Performance targets are identical to the puissance at the Horse of the Year Show. You know the one - the high-jump competition, where the poor, dumb horse is brought into the ring, asked to clear a massive red wall, and as a reward for its heroic effort is promptly brought back and asked to do it all over again, only higher. 
I've never felt anything but admiration for those puissance horses which, not so dumb at all, swiftly realize that the game is a bogey. Why on earth should they bother straining heart, sinew and bone to leap higher than their own heads, only to be required to jump even higher? And then possibly higher still.

Hard work and willingness, ponders the clever horse as he chomps in the stable that night, clearly bring only punishment. And so next time he's asked to canter up to the big red wall, he plants his front feet in the ground and shakes his head. And says, what do you take me for - an idiot? (Melanie Reid, "The Times", Monday, February 4, 2008).

Here puissance horses are compared to people, riders to managers, the red walls as obstacles to the targets people have to achieve, having to jump over the obstacles to being subject to assessment, clearing the obstacles to achieving the targets, raising the obstacles to giving more difficult targets, the Horse Show to life, and so on and so forth. This elaborate metaphorical analogy provides a great deal of structure for the text.

In sum, in several cases, once introduced, conceptual metaphors (or metaphorical analogies) appear to have the effect of taking over what one says or thinks about a particular subject matter. Conceptual metaphors (including metaphorical analogies) can dominate, or "govern", an entire discourse or just a stretch of it, creating intratextual coherence for the discourse.

However, unlike the existence of discourses such as the example above, most of the time we find imagistically incompatible metaphors in media discourse. The kind of example concerning the puissance is the exception, rather than the rule. The metaphorical images used by authors in media discourse tend to be incompatible, that is, people mix their metaphors, as can be seen in the quote below: 
While preaching the pro-business gospel, he has done nothing to stop the tide of EU rules and red tape from choking Britain (Kimmel 2010).

Kimmel's example comes from a newspaper article, in which Tony Blair is criticized for his policy. The incompatible metaphors in the example are tide and red tape. Tide, in addition to its literal meaning, has the metaphorical meaning "a large amount of something" and red tape has that of "complicated and unnecessary bureaucracy". The question then is: Why are imagistically incongruent metaphors selected at a particular point in discourse?

The topic of discourse, that is, the target domains, or frames, we are developing in the course of producing and understanding (metaphorical) discourse (such as Blair's policy) have many different aspects to them, and these aspects normally require a variety of different source domains, or frames, for their conceptualization. Given a target domain, or frame, certain elements of the domain need to be employed and linguistically expressed. These elements are the meanings that a speaker wants to express in the course of producing the discourse. When expressing a target domain meaning, the speaker needs to employ an element that either comes from the target domain directly or from a source domain that is systematically linked to that target by means of a set of mappings. In the former case, the speaker speaks literally (i.e., directly), in the latter, he or she speaks metaphorically (i.e., indirectly).

The target domain meanings form a part of aspects of the target domain, such as progress, functioning, control, stability of structure, and so on. There are, in many cases, conventional source domains whose main function is to metaphorically express such aspects of target domain concepts (see Kövecses 2002/2010). In other words, they are source concepts that profile these aspects of the target domain. For instance, the source domain of JOURNEY typically profiles the notion of "progress", that of MACHINE profiles "functioning", that of WAR and FIGHTING profile "control", that of BUILDING profiles "stability of structure", that of the HUMAN BODY profiles "(hierarchical) 
structure" and "appropriate condition (of some structure)", and so on. In some of my publications, I refer to these as the "meaning foci" of a source domain (see, e.g., Kövecses 2002/2010, 2005). Given these meaning foci, we get generic metaphors like PROGRESS IS A JOURNEY, FUNCTIONING IS (THE WORKING OF) A MACHINE, CONTROL IS WAR/FIGHTING, STABILITY OF STRUCTURE IS A BUILDING, and several others. These are metaphors that apply to a large number of targets; that is, they have a wide scope (Kövecses 2002/2010).

If this is the case, we should not expect discourses about a particular target domain topic to be expressed by large sets of homogeneous metaphorical linguistic expressions (i.e., expressions that belong to the same source domain). Just the opposite, given a particular target domain and its various aspects, we should expect metaphorical linguistic expressions to occur in the discourse that capture and are based on the typical source domains that are conventionally employed to express and capture those aspects. In other words, no matter how incompatible the images evoked by tide and red tape are, they are selected because they can render (indirectly) the elements required by the different aspects of the target domain (here, Blair's policy) at a certain point in the discourse.

In sum, the intratextual use of conceptual metaphor does not necessarily produce metaphorically homogenous discourse. In most cases, a variety of different conceptual metaphors is used in particular media and other texts. This is a natural phenomenon, given the nature of conceptual metaphors as based on the general structure of concepts (i.e., that the concepts have various aspects and we use the conceptual metaphors to comprehend those aspects).

\section{Contextual influence on metaphorical media discourse}

In my Where metaphors come from (2015), I argue that (the knowledge or awareness of) our experiences in the local and global contexts can prompt the use of particular metaphors - either conventional or novel ones. I have used a variety of terms for this 
process; I suggested that the various contextual factors can motivate, trigger, prompt, facilitate, shape, etc., the use of a metaphor in discourse. I believe the best way to characterize these mental events is to think of them as instances of "priming". Priming is a well-studied cognitive process used extensively in psychological and psycholinguistic experiments with a sizeable literature (see, e.g., Boroditsky \& Ramscar 2002; Casasanto 2009; Gibbs \& Colston 2012; and several other studies). Importantly, priming is based on the simulation of some experience in the situational, discourse, bodily, and conceptual-cognitive context (see Kövecses 2015).

To take an example of priming from the literature that is not based on conceptual metaphor theory, let us look at a study by Kahneman concerning the importance of priming in conceptualization (Kahneman 2011). Kahneman gives us a flavor of the power of priming effects in metaphorical thought as well. This is what he writes concerning an experiment that involves metaphorical thought:

Other experiments have confirmed Freudian insights about the role of symbols and metaphors in unconscious associations. For example, consider the ambiguous word fragments $W_{-} H$ and $S_{-} P$. People who were recently asked to think of an action of which they were ashamed are more likely to complete those fragments as WASH and SOAP and less likely to see WISH and SOUP. Furthermore, merely thinking about stabbing a coworker in the back leaves people more inclined to buy soap, disinfectant, or detergent than batteries, juice, or candy bars (Kahneman 2011: 56).

In a similar way, my proposal is that the contextual factors of different kinds can all prime the use of particular metaphors in context - simply because the choice of the metaphors would be coherent with the contextual factors functioning as primes. Kahneman does not mention it, but his experiment involves the highly conventional conceptual metaphor BAD / IMMORAL IS DIRTY (as in "dirty business") and some of the actions (cleaning) that are associated with this metaphorical source domain). Various kinds of experiences in real life can prime people to choose particular metaphors (metaphorical source domains) in the course of conceptualizing target domains. 
One kind of contextual factor that can prime a speaker/writer to use a particular metaphor is the immediate linguistic context itself. Suppose, for example, that we are talking about the progress of a particular process and want to say that the progress has become more intense. There are many ways, in which this can be done. We can say that the progress accelerates, speeds up, gains momentum, moves faster, picks up or gathers speed, and many others. These are all relatively conventional ways of talking about an increase in the intensity of a process. They are all based on the conventional generic-level mapping INTENSITY IS SPEED, as it applies to the concept of progress (in relation to a process). The larger metaphors within which the mapping INTENSITY IS SPEED works are also well established ones: PROGRESS IS MOTION FORWARD and, even more generally, EVENTS ARE MOVEMENTS.

\section{The case of headlines}

However, the particular concepts that refer to the specific process we are talking about may influence the (unconscious) choice of the linguistic metaphorical expression in talking about the intensity of the progress at hand. The linguistic metaphors we actually use may be much less conventional than the ones mentioned above. As an example, consider a headline from "The Wall Street Journal Europe" (January 6, 2003). It reads:

The Americanization of Japan's car industry shifts into higher gear.

Here, the process is the Americanization of Japan's car industry and the suggestion is that it has become, or is becoming, more intense. Instead of describing the property of "increase in intensity" by any of the conventional linguistic metaphors above, or, as a matter of fact, by a large number of additional ones that could be used (such as galloping ahead), the author uses the relatively unconventional linguistic metaphor shifts into higher gear.

I propose that this particular expression is selected because of the influence of the immediate linguistic context, that is, the concepts that surround the conceptual slot 
where we need an expression to talk about "an increase in intensity" (of the progress of a process). Since the process is that of the Americanization of Japan's car industry, we find it natural and highly motivated that the author of the utterance uses the expression shifts into higher gear in that conceptual slot in the discourse.

Aitchison (1987) made an interesting observation that bears on this issue. She noted that in newspaper articles and headlines about (American) football games, the names of the teams may select particular metaphors for defeat and victory. She found such examples as follows in the sports pages of American newspapers: "Cougars drown Beavers", "Cowboys corral Buffaloes", "Air Force torpedoes the Navy", "Clemson cooks Rice" (Aitchison 1987: 143). Metaphors used in these sentences are selected on the basis of the names of football teams. Since beavers live in water, defeat can be metaphorically viewed as drowning; since cowboys corral cattle, the opponent can be corralled; since navy ships can be torpedoed, the opponent can be torpedoed, too; and since rice can be cooked, the same process can be used to describe the defeat of the opponent. The metaphors in the above sentences indicate that the target domain of DEFEAT can be variously expressed as drowning, corralling, etc., the choice depending on the concepts (in this case, corresponding to the names of the teams) that make up the utterances in which the metaphor is embedded.

This kind of context-induced metaphor use is a robust phenomenon in headlines. We find hundreds of examples for this every day. They seem to have clear pragmatic functions, such as trying to be witty or humorous, drawing the readers' attention, being sensational, etc. The exact nature of the process is not yet fully understood and described, nor do we have a full list of its potential pragmatic functions, but it seems that this way of creating headlines is a true megatrend in media discourse. 


\section{Potential misuses of metaphor in media disourse}

One of the most interesting and important properties of conceptual metaphors is that they can create virtual realities. Metaphorically created virtual realities can offend, shock, stigmatize, make fun of, belittle, distort, lie, deceive, manipulate, and so on. The virtual reality in which I feel I have to protect myself from my body odor is a manipulative reality. The virtual reality in which a man hugs his car and loves it like a family member is a deceptive reality designed (or even calculated) to improve sales. Creating fears in people and playing with their emotions are features of many conceptual metaphors in advertisements. This leads to an ethical issue in the world of business (as in advertisements, marketing, etc.): How far can we go in creating metaphorical virtual realities? In order to understand and evaluate the ethical appropriateness of such conceptual metaphors, we need to understand the structure and function of these metaphors and their hidden implications. Conceptual metaphor theory could greatly contribute to this undertaking.

My previous examples for this phenomenon came from advertisements. A similar concern in this connection is voiced by Brown (2008) in his study of metaphors in marketing. Brown distinguishes three stages of metaphor development:

... a three stage model of metaphor development can be tentatively posited: (1) an ornamental era, when figures of speech were considered vulgar add-ons; (2), an elemental era, when the realization dawned that figurative thinking was not only unavoidable but invaluable; and (3) a detrimental era, where anthropomorphic tropes have become so commonplace they're tantamount to vermin. The next stage, inevitably, will involve interbreeding, memetic modification and a master-race of mutant monstrosities that feed on the cash cows and greedy pigs of capitalism. A cull is called for. Extermination is the only answer. Action must be taken against the rapidly-breeding rabbits of corporate life!

What this passionate and, probably also, exaggerated call misses (or leaves out of consideration) is the reasons why the third stage can occur to begin with. What needs to be accounted for is why the "detrimental era" can produce the negative effects it does. The explanation, I suspect, involves both the unconscious priming process that 
characterizes the creation of some metaphors and the very deliberate choice of source domains in other cases, such as the car and deodorant examples.

\section{Conclusions}

In the paper, I argued that the study of metaphors from a CMT perspective lends a cognitive dimension to the study of media communication. The study of the cognitive dimension of metaphor is a valuable tool in understanding how and why the media creates its messages in its various modalities.

An extremely important aspect of this is that conceptual metaphors not only shape media language (in its most general sense), but that they also construct virtual realities.

Conceptual metaphors can structure media discourse both intertextually and intratextually, but they can also account for seemingly incoherent media discourse, which seems to be the general case. Conceptual metaphor theory can explain why we mix metaphors in a natural way.

Media discourse is heavily context dependent as a result of the effect of priming. Headlines are especially prone to contextual influence for a variety of pragmatic reasons. Capturing the structure of this cognitive process makes it possible to identify dominant trends in media discourse.

The potential of metaphor to create virtual reality raises ethical issues in connection with certain types of media metaphors. The study of such issues is only possible if we study the conceptual metaphors used in the media in their depth and complexity.

\section{Abbreviations}

CMT - Conceptual metaphor theory 


\section{References}

Aitchison, J. (1987). Words in the mind. London: Blackwell.

Boroditsky, L. \& Ramscar, M. (2002). The roles of body and mind in abstract thought. In Psychological science, 13 (2), p. 185-189.

Brown, S. (2008). Are marketing's metaphors good for it? In The marketing review, 2008, 8 (3). DOI: 10.1362/146934708X337645. Available at:

https://www.researchgate.net/publication/316605704_Are_Marketing\%27s_Metapho rs Good For It The Marketing Review Vol 8 No 32008

Casasanto, D. (2009). Embodiment of abstract concepts: Good and bad in right and left handers. In Journal of experimental psychology: General, 138 (3), p. 351-367.

Cienki, A. \& Müller, C. (2008). Metaphor, gesture, and thought. In The Cambridge handbook of metaphor and thought. Gibbs, R.W. Jr. (ed.). Cambridge: Cambridge University Press, p. 483-501.

Forceville, C. (2008). Metaphors in pictures and multimodal representations. In The Cambridge handbook of metaphor and thought. Gibbs, R.W. Jr. (ed.). Cambridge: Cambridge University Press, p. 462-482.

Gibbs, R. \& Colston, H. (2012). Interpreting figurative meaning. Cambridge-New York: Cambridge University Press.

Kahneman, D. (2011). Thinking, fast and slow. London: Penguin.

Kimmel, M. (2010). Why we mix metaphors (and mix them well): Discourse coherence, conceptual metaphor, and beyond. In Journal of pragmatics, 42, p. 97-115. Kövecses, Z. (2017). Conceptual metaphor theory. In The Routledge handbook of metaphor. Semino, E. \& Demjén, Zs. (eds.). Oxford: Routledge, p. 13-27.

Kövecses, Z. (2006). Language, mind, and culture. A practical introduction. OxfordNew York: Oxford University Press.

Kövecses, Z. (2002 / 2010). Metaphor. A practical introduction. Oxford-New York: Oxford University Press.

Kövecses, Z. (2005). Metaphor in culture. Universality and variation. Cambridge-New York: Cambridge University Press. 
Kövecses, Z. (2015). Where metaphors come from. Reconsidering context in metaphor. Oxford-New York: Oxford University Press.

Lakoff, G. \& Johnson, M. (1980). Metaphors we live by. Chicago: The University of Chicago Press.

\begin{tabular}{|l|l|l|}
\hline \multicolumn{1}{|c|}{ Contact data } \\
Zoltán Kövecses \\
DSc. (Linguistics) \\
Professor Emeritus
\end{tabular}

\section{Résumé}

In the paper, I discuss three large issues relating to media language. (1) According to conceptual metaphor theory (CMT), metaphor is not simply a property of language it is a property of human cognition. How does this view affect the way we see the conceptual system that characterizes the main participants of communication in the media - those who create and those who receive its messages? I argue that CMT offers a unified framework within which we can explain a variety of phenomena in media communication that have not been observed previously as being related. (2) How do conceptual metaphors structure the language (and thought) used by the media? Is it the case that particular conceptual metaphors structure particular discourses? I distinguish between intertextual and intratextual structuring. I suggest that the relationship between conceptual metaphors and media discourse is such that, contrary to our expectations, no single conceptual metaphor structures texts in the majority of cases. (3) Is the metaphorical mind of the participants of media communication a "selfcontained" mind immune to the influence of context or is it affected by it? If the latter, what is the cognitive mechanism that can produce contextual influence on metaphor use? And if there is contextual influence that results in metaphors, can this influence 
be manipulated? I argue that the mind that participates in media communication is very much influenced by a variety of contextual factors, as proposed by Kövecses (2015).

Keywords: media discourse, conceptual metaphor, virtual reality, coherence of media discourse, contextual effects, priming.

Article was received by the editorial board 02.05.18;

Reviewed 14.05.18. and 20.05.18.

Similarity Index 34\% 